\title{
Estrella Montolío y Mario Tascón, El derecho a entender. La comunicación clara, la mejor defensa de la ciudadanía*
}

(2020) Catarata

Madrid, $192 \mathrm{pp}$.

Germán J. Arenas Arias

Instituto Universitario de Investigación en Estudios Latinoamericanos (IELAT)

Universidad de Alcalá

ORCID ID 0000-0003-1526-7181

german.arenas@edu.uah.es

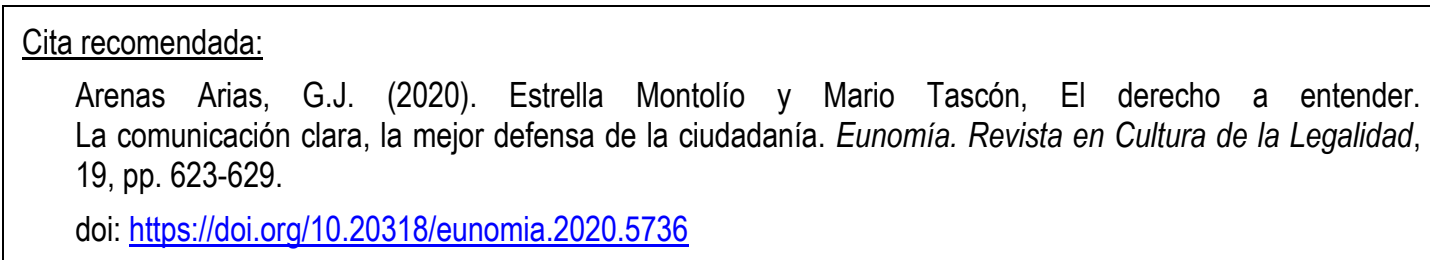

El fin del estado de alarma en España y el inicio de una «nueva normalidad», para continuar con las medidas de contención de la COVID-19, coincidió con la publicación del nuevo libro El derecho a entender, de la profesora Estrella Montolío y el periodista Mario Tascón. Su lectura es estimulante y me anima a escribir esta recensión por dos motivos fundamentales. El primero tiene que ver con la oportunidad del momento de su aparición: la crisis global que estamos viviendo y la consecuente proliferación normativa imponen la necesidad de simplificar el acceso de los ciudadanos para que entiendan, conozcan y utilicen las normas derivadas de la pandemia. El derecho a entender y la comunicación clara podrían funcionar como un vehículo para allanar esa necesidad. El segundo motivo son los nuevos elementos teóricos y prácticos que el

\footnotetext{
* La presentación -virtual- de El derecho a entender. La comunicación clara, la mejor defensa de la ciudadanía se llevó a cabo el día 1 de julio de 2020 y estuvo acompañada del anuncio de un proyecto de inteligencia artificial para medir el nivel de claridad u oscuridad en el lenguaje administrativo español. Con seguridad, esto podrá motivar un ejercicio de innovación pública en el ámbito gubernamental español y latinoamericano.
} 
libro aporta a la agenda de investigación académica y a la discusión pública relacionadas con el proyecto y movimiento del lenguaje claro.

El libro lleva como subtítulo La comunicación clara, la mejor defensa de la ciudadanía, y es producto de la colaboración entre Estrella Montolío, catedrática de Lengua Española en la Universidad de Barcelona y Mario Tascón, quien dirige Prodigioso Volcán y ha presidido la Fundación del Español Urgente (Fundéu). También es un trabajo riguroso que se enmarca en una creciente literatura, dedicada a problematizar, discutir y visibilizar la importancia de la claridad en el lenguaje jurídico y la necesidad de comprenderlo. En el ámbito hispanoamericano, Carretero (2005, 2019); Montolío (2012); García Calderón (2012); Poblete y Fuenzalida (2017); Relinque (2017); López Medina (2018); González Zurro (2018); De Cucco Alconada (2019); Núñez Sánchez (2019); y Moreu Carbonell (2020) representan una muestra significativa de esa bibliografía.

Desde el prólogo, firmado por el catedrático de Derecho Administrativo de la Universidad de Barcelona, Juli Ponce Solé, el nuevo libro de Montolío y Tascón ya ofrece un tratamiento oportuno y esclarecedor sobre el denominado derecho a entender. "Que los ciudadanos/consumidores (así expresados, pues esta es nuestra doble faceta) entiendan las comunicaciones del sector público y del sector privado son un derecho subjetivo que ostentan, el cual genera auténticas obligaciones jurídicas para los entes públicos y las empresas privadas» (p. 5). Aunque cada una de las piezas que conforman el ordenamiento jurídico no se refiera explícitamente a ese derecho, «la obligación de diligencia de los gobiernos y administraciones de hacerse comprender forma parte intrínseca de los principios de buen gobierno y del derecho a una buena administración» (p. 8). La inobservancia de esa dimensión intrínseca atenta directamente contra los principios fundantes del Estado de Derecho: legalidad, seguridad jurídica, racionalidad.

El lenguaje claro es el instrumento principal que suele ser formulado cuando se habla de la existencia de un derecho a entender, y aquí se propone, además, considerarlo como un nudge que, en el ámbito de las políticas públicas y la economía conductual, contribuye «en la mejora y efectividad de las decisiones públicas y en el desarrollo de mejores regulaciones» (p. 10). Esa perspectiva es una invitación retadora y muy pertinente.

«¿En alguna ocasión ha recibido un documento de algún ministerio, ayuntamiento u organismo público en el que no ha entendido nada? ¿Recuerda el folleto de algún producto o servicio del que difícilmente ha comprendido cuáles eran las condiciones?» (p. 13). Estas son dos preguntas que los autores sugieren en el primer párrafo de la introducción para advertir sobre las intenciones y el contenido de su libro. Se trata de un alegato, como dicen, a favor de la claridad en la comunicación con la ciudadanía «porque para ser ciudadanos con plenos derechos y participar en la construcción del espacio público, el primer paso es entender lo que las instituciones y las empresas nos explican, nos piden... o nos ocultan» (p. 15). Los autores hablan del derecho a entender y no del derecho a comprender porque «no es lo mismo (...) la comprensión requiere un proceso interno, es hacer propio lo que se entiende y actuar en consecuencia» (p. 15). Más adelante volveré a ello.

La estructura que sigue el libro es de siete capítulos y se pueden identificar tres ejes importantes. El primero es un marco histórico y conceptual alrededor del movimiento por el lenguaje claro y el derecho a entender que le acompaña. La segunda parte expone que las nuevas tecnologías de la información, los proyectos de inteligencia artificial y las prácticas user experience (UX) pueden favorecer los procesos de comunicación pública y privada y el derecho a entender en el ecosistema 
digital. Finalmente, el libro aborda la cuestión sobre "¿cómo se pasa de una comunicación burocrática a una comunicación democrática?» (p. 131). La respuesta son nueve pasos para alcanzar una comunicación clara, plenamente aplicable en las administraciones públicas, para democratizar el acceso a la información y empoderar a los ciudadanos.

Me propongo con esta reseña resaltar y comentar brevemente algunos elementos encontrados dentro de los tres ejes del libro.

Sobre el primero, merece la pena destacar el lugar que los autores reconocen a la figura de la sociedad civil y a los activistas del plain language movement (movimiento del lenguaje claro). «Fueron las revueltas cívicas que se iniciaron en los años cincuenta y se extendieron hasta finales de los setenta las que marcaron un punto de inflexión en el derecho a entender. Las reivindicaciones de la sociedad civil crearon una corriente imparable en la defensa de la claridad» (p. 20). Los movimientos antiguerra en Estados Unidos que rechazaban cartas de reclutamiento incomprensibles (p. 21); las asociaciones de consumidores financieros que reclamaron la posibilidad de entender íntegramente los contratos por firmar (p. 22), y más concretamente, la campaña plain english liderada por Chrissie Maher en Liverpool, para simplificar el proceso de solicitud de ayudas sociales del Estado ( $p$. 23), son los ejemplos más relevantes de acción colectiva que luego van a propiciar el surgimiento y evolución del movimiento de lenguaje claro.

Movimiento que, como ha señalado Muñoz Machado, «ha llevado consigo, en todos los Estados de Derecho avanzados, por un lado, la introducción de medidas conducentes a la mejora de la calidad, y, sobre todo, claridad, previsibilidad y fácil comprensión de la legislación, y por otro, la aprobación de planes, programas y normas destinadas a la mejora de la calidad lingüística de los textos judiciales y administrativos» (2017, p. 15). Ello ha sido posible, en gran parte, gracias a los esfuerzos colectivos que Montolío y Tascón retratan en su libro.

La internacionalización del movimiento, la necesidad de clarificar el discurso jurídico y la conformación de grupos de presión (p. 25) facilitaron en la Unión Europea y en América Latina, iniciativas como Fight the Fog, Clear Writing Campaign, Plain Swedish Group, la Comisión para la Modernización del Lenguaje Jurídico y las Redes de Lenguaje Claro creadas en México, Chile, Argentina y Colombia. En el proceso de construcción de esas iniciativas, la discusión -jurídica y política- sobre la existencia de un derecho a comprender ha aumentado de manera considerable. En el Informe de la Comisión para la Modernización del Lenguaje Jurídico en España (2011) y en la Cumbre Judicial Iberoamericana (2015) hay referencias explícitas sobre un derecho ciudadano a comprender la justicia: «la ciudadanía tiene derecho a comprender, sin la mediación de un "traductor", las comunicaciones verbales o escritas de los profesionales del derecho».

En trabajos posteriores se ha advertido que «el nuevo derecho a comprender sería aquel que corresponde a los ciudadanos a la hora de exigir de los poderes públicos el esfuerzo institucional que sea preciso para que puedan, sin necesidad de conocimientos jurídicos, ser entendidos los actos, orales o escritos, que son realizados para la correcta elaboración, interpretación o aplicación de las leyes» (García Calderón, 2012, p. 176). «El derecho a comprender debe materializarse en medidas que promuevan la claridad en el uso de las comunicaciones por parte de todos los poderes» (Carretero, 2019, p. 239). «Los requisitos básicos para un Derecho comprensible [son]: claridad (lenguaje claro), accesibilidad (lenguaje accesible) y neutralidad (lenguaje inclusivo)» (Moreu Carbonell, 2020, p. 347). Más aún, «la conformación conceptual del derecho a comprender supone la necesidad, en primer 
lugar, de considerar los aspectos constitucionales a los que el derecho afecta en su despliegue y aquellos otros derechos fundamentales implicados en su ejercicio, lo que permitirá la delimitación de su contenido esencial y adicional y sus propios límites» (Núñez Sánchez, 2019, p. 110). No obstante, concluye Núñez Sánchez, «dotarlo de un verdadero estatuto de derecho, ya sea por vía legislativa o jurisprudencial, sigue siendo una tarea pendiente» (2019, p. 109).

Montolío y Tascón no pretenden abarcar esta cuestión, pero sí citan a Silvia Bianco, consejera de la Magistratura de la Ciudad de Buenos Aires, para brindar una definición aproximada: «El derecho a comprender es la posibilidad de pensar de manera crítica y de practicar la plena libertad y, en ese sentido, la aclaración de conceptos jurídicos mediante la simplificación de sus definiciones es una herramienta más para democratizar la justicia» (p. 87). Con esto último, me atrevo a añadir que el lenguaje claro no es la única herramienta de análisis para justificar conceptualmente un derecho a comprender. Tampoco es la única posibilidad para democratizar la justicia, como bien lo expresa la cita de Bianco. Es sólo un instrumento que, eso sí, contribuye en el acceso, la confianza y la seguridad jurídica, y que necesita mayor discusión y difusión para dimensionar sus verdaderos alcances. Si, efectivamente, estamos frente a un derecho, particularmente apuesto por una idea de adquisición de criterios mínimos que le permitan al individuo tomar decisiones autónomas sobre los asuntos que le afectan.

Sobre el segundo eje que he podido identificar en el libro de Montolío y Tascón, quisiera resaltar las referencias sobre user experience, diseño emocional y servicios inclusivos. En el campo de la información pública en general, y de la información jurídica, específicamente, Poblete y Fuenzalida (2017) y Moreu Carbonell (2020) han sugerido un "giro lingüístico hacia el ciudadano», pues este debe ser el centro de la actividad estatal. Con esa lógica, existe un amplio margen para mejorar la experiencia de los usuarios/ciudadanos en su relación con el Estado. Los autores de El derecho a entender completan con acierto esa sugerencia.

En una época en la que preferimos más la pantalla que el papel, «acceder a la información, comprenderla y poder usarla» (p. 41) es una cadena de acciones que depende fundamentalmente del diseño con que están presentados los productos o servicios. "Solicitar una beca, contratar un seguro, poner en marcha un nuevo electrodoméstico..., incluso algo tan sencillo como comprar un billete de metro cuando visitamos una ciudad. A menudo, situaciones cotidianas de este tipo pueden resultar exasperantes porque hay pasos del proceso que no entendemos, es decir, hemos obtenido una mala experiencia de usuario. Y en la base de este enfado suele haber, casi siempre, falta de claridad, falta de sencillez y falta de empatía por parte de quienes diseñan el proceso» (p. 43). Por esa razón, los autores insisten en que para hacer efectivo un derecho a entender es indispensable que las personas tengan una experiencia de usuario satisfactoria. Dicha experiencia está atravesada por el lenguaje ${ }^{1}$.

Los autores suscriben la idea de que «no existe normalmente una alternativa a los servicios que presta el Estado, por lo que tienen que funcionar para todos. Crear un servicio inclusivo significa asegurar que quien lo necesita pueda usarlo de la forma más sencilla posible» (p. 49). Con ello indican que el sector empresarial y el estatal deben hacer un esfuerzo adicional por promover una nueva cultura de servicio que tenga en cuenta, entre otros asuntos, que «el lenguaje es una herramienta

\footnotetext{
${ }^{1}$ En enero de 2020 se publicó el trabajo The Effects of Jargon on Processing Fluency, Self-Perceptions, and Scientific Engagement, cuyos autores constatan que «el uso de palabras difíciles y especializadas da una señal a las personas que no las entienden: no pertenecen a una comunidad. Se pueden explicar los términos, pero ya sienten que el mensaje no es para ellos». Ver Schulman, Dixon y Bullock (2020).
} 
increíblemente poderosa para crear un sentido de empoderamiento, orgullo, identidad y propósito» (p. 56).

La neurociencia y la neurolingüística entran en juego dentro del libro de Montolío y Tascón. De ahí también la novedad y originalidad que aportan para recomendar que en la relación Estado-ciudadanos es conveniente reducir la presunción de complejidad. "Cuando vemos un sitio con apariencia compleja, nuestro cerebro lo registra a gran velocidad y en general, no lo percibimos como atractivo. También sucede lo contrario: el cerebro decide en cuestión de décimas de segundos si un documento va a ser fácil de entender» (p. 95). Adicionalmente, los dos autores advierten que «los mejores textos y el mejor diseño fracasarán si el ciudadano no sabe qué hacer, por dónde buscar o qué botón pulsar» (p. 108). Ello es consecuencia de la complejidad innecesaria que las instituciones suelen incorporar en sus procedimientos con efectos adversos en los planes individuales.

Por ejemplo, en agosto de 2019, la Corte Constitucional de Colombia resolvió una acción de tutela formulada por un estudiante que perdió un crédito educativo al equivocarse en el complejo formulario que debía entregar al Instituto Colombiano de Crédito Educativo y Estudios Técnicos en el Exterior -ICETEX-. La Corte afirma en esa sentencia que «las autoridades públicas están en la obligación de establecer formularios claros en los que la información que se pide consignar a la ciudadanía, pueda ser allegada sin hacer incurrir en ambigüedades o imprecisiones a los administrados. Lo anterior es condición de posibilidad para la materialización del principio de eficacia y la realización de la justicia material» (Corte Constitucional de Colombia, Sentencia T-340/19). Como puede verse, la recomendación de Montolío y Tascón no es un tema menor. Aplicar técnicas y mecanismos que mejoren la experiencia del usuario y orienten adecuadamente a los ciudadanos puede incidir en el goce y disfrute de derechos fundamentales. En el caso que planteo, se trata del derecho a la educación superior y debido proceso.

Por último, me refiero al tercer eje donde se encuentra la propuesta clave que recoge el nuevo libro. Se trata de la comunicación clara, esto es, «transmitir de forma fácil, directa, transparente, simple y eficaz información relevante para la ciudadanía, por cualquiera de los diferentes canales (papel, teléfonos móviles, ordenadores y otros dispositivos) y adaptada a sus particularidades» (p. 134). Desde luego, debe incluir todos los elementos basados en user experience y de diseño que previamente fueron reportados en el libro. El reto es «crear, liderar y normalizar una nueva cultura ciudadana de comunicación clara» (p. 148) que, según los autores, "reduce la ansiedad que provoca la difícil comprensión de documentos y procedimientos administrativos, agiliza trámites, democratiza el acceso a la información, promueve la participación en un Estado de Derecho, hace más eficaz la comunicación, mejora la reputación de los organismos y empodera a la ciudadanía» (pp. 149-150).

El Ayuntamiento de Madrid inició con Estrella Montolío y Mario Tascón un proyecto de comunicación clara para intervenir los documentos que comunicaban las multas de tránsito en 2016. El resultado fue un documento sencillo, claro y fácil; «los pagos ahora se hacen más rápidos, las reclamaciones circulan de forma más fluida y se han reducido las dudas y llamadas a los servicios de atención municipales» (p. 131). En América Latina contamos con algún caso similar que incluye información de resultados con carácter cuantitativo².

\footnotetext{
2 Se trata del estudio del Banco Interamericano de Desarrollo The Importance of Clarity: Impacts of Colombia's 'Lenguaje Claro' Program on Reducing Administrative Burdens (2019), el cual ha señalado que la aplicación del programa de Lenguaje Claro del Departamento Nacional de Planeación, en concreto, la simplificación de una carta catastral en el Distrito de Bogotá, disminuye la carga
} 
Montolío y Tascón, mediante una serie de nueve pasos (p. 151 y siguientes), proponen un modelo de comunicación clara que incentive un diálogo participativo con la ciudadanía (y también con los clientes). No conciben un proyecto de comunicación clara si de manera anticipada las organizaciones no se preguntan quiénes son los que recibirán la información, qué necesitan saber, qué harán con la información, qué decisiones podrán tomar, en qué momento recibirán los mensajes o qué conocimiento previo tienen del tema. Sostienen, finalmente, que «un ciudadano es un intérprete activo del que esperamos una respuesta, casi nunca es un simple receptor del mensaje. El objetivo de la comunicación clara no es la mera producción de documentos, sino la generación de reacciones deseadas en la ciudadanía» (p. 139). Esta misma idea, enmarcada en un «proyecto de democracia republicana donde los ciudadanos participan de manera activa en los asuntos públicos (...) y de manera individual o colectiva, tienen la posibilidad de controlar y disputar decisiones» (Wences y Güemes, 2016, p. 28), me devuelve al prólogo de Ponce Solé, cuando hace referencia al nudging como método para incentivar conductas deseables de la ciudadanía.

Si el lenguaje claro, o más ampliamente, la comunicación clara, «no solo protege derechos individuales y colectivos, sino que también puede ser un magnífico instrumento para el logro de los intereses generales que han de perseguir nuestros poderes públicos» (p. 12), estamos frente a un desafío académico relevante que pasa por situar este debate en el ámbito de «las tecnologías de política pública que buscan incrementar la eficiencia de los Gobiernos y, en consecuencia, los niveles de confianza y cooperación» (Güemes, 2017, p. 47).

Los autores reiteran a lo largo de su obra que este es un asunto marcado por la convergencia de varias disciplinas. No puede ser otra manera. Juristas, lingüistas, diseñadores, comunicadores, traductores, expertos en usabilidad, y también los politólogos, tienen mucho que decir todavía.

\section{Bibliografía}

Carretero González, C. y Garrido, R. (2005). Derecho y lenguaje: perspectivas interdisciplinares. En M. Romana García, (ed.), II AlETI. Actas del I/ Congreso Internacional de la Asociación Ibérica de Estudios de Traducción e Interpretación.: AIETI, Madrid, pp. 713-727.

Carretero González, C. (2019). Comunicación para juristas, Madrid : Tirant Lo Blanch. Corte Constitucional de Colombia, Sentencia T-340 de 2019. Magistrado Ponente: Alberto Rojas Ríos.

De Cucco Alconada, C. (2019). Manuel de escritura de textos jurídicos en lenguaje claro, Buenos Aires: Hammurabi.

\footnotetext{
administrativa para la entidad y para la ciudadanía. El efecto de la carta simplificada en la presentación de cualquier tipo de solicitud fue negativo $(-0,025)$ y registró un nivel similar cuando se incluyeron otras variables de control $(-0,023)$. Esto significa que los destinatarios de la carta simplificada tenían una probabilidad de 2,5 puntos porcentuales (equivalentes a un $20,7 \%$ ) menos de presentar cualquier tipo de solicitud después de recibir la notificación de revisión del avalúo por parte de Catastro $(18,5 \%$ al incluirse otros controles). Si se restringe el análisis exclusivamente a las solicitudes de reposición, quienes recibieron la carta simplificada tenían, en promedio, una probabilidad de 3,5 puntos porcentuales (equivalentes al 30\%) menos de presentar una solicitud de reposición (valor significativo al nivel del 10\%). Ver Cuesta, Reyes y Roseth (2019).
} 
García Calderón, J. (2012). Un nuevo derecho a comprender. Cuadernos de derecho y comercio, 57, pp. 141-178.

González Zurro, G. (2018). Sentencias en lenguaje claro. Thomson Reuters - La ley, pp. 1-6.

Güemes, C. (2017). ¿Nudge en América Latina? Incidir en el comportamiento individual, obtener resultados colectivos. Revista del CLAD Reforma y Democracia, 68, pp. 43-74.

López Medina, D. (2018). Manual de escritura jurídica, Bogotá: Legis.

Ministerio De Justicia De España (2011). Informe de la Comisión de Modernización de Justicia. Recomendaciones.

Montolío, E. (2012). Hacia la modernización del discurso jurídico. Contribuciones a la I Jornada sobre modernización del discurso jurídico español. Barcelona: Universitat de Barcelona.

Moreu Carbonell, E. (2020). Nuestro lenguaje: el giro lingüïstico del derecho. Revista de Derecho Público: Teoría y Método, 1, pp. 313-362.

Muñoz Machado, S. (2017). Libro de estilo de la justicia. Madrid: Espasa.

Núñez Sánchez, A. (2019). El derecho a comprender. Lenguaje jurídico y comunicación, Revista del Ministerio Fiscal, 8, pp. 96-113.

Poblete, C. y Fuenzalida, P. (2018). Una mirada al uso de lenguaje claro en el ámbito judicial latinoamericano. Revista de Llengua i Dret, Journal of Language and Law, . 69, pp. 119-138.

Relinque Barranca, M. (2017). El proceso de modernización del lenguaje jurídico en el Reino Unido, los Estados Unidos y España y su reflejo en el lenguaje utilizado por los jueces. FITIS Pos International Journal Public Service Interpreting and Translation, 4, pp. 85-101.

Wences, I. y Güemes, C. (2016). Democracia republicana y confianza en América Latina: la esperanza que no llega, que no alcanza. Andamios. Revista de investigación social, 13(30), pp. 13-37. 